\title{
An analysis of the boiler and heat exchanger manufacturing industry in the US using Porter's Five Forces Framework
}

\author{
Jerry Chik ${ }^{1}$ \\ ${ }^{1}$ School of Trades, Agriculture, and Environment, Grande Prairie Regional College
}

Key points:

1. Government policies may influence the competitive landscape if they provide appealing incentives to buyers for purchasing boilers and heat exchangers with higher efficiencies and lower rates of emission. 2. Technological advances and increasingly stringent regulatory requirements for efficient and lowemission products will shift power towards industry competitors and new entrants with patented and differentiated products and services.

3. Technological progress and the challenges posed by imports through increasing globalization could substantially change and disrupt the industry by reducing barriers to entry and by raising the threat of substitutes.

\section{Abstract}

As global trade expands and technological progress is being made in developing countries, manufacturers of boilers and heat exchangers in the US are facing increasing import competition while industry profitability is competed away from industry rivals, market entrants, as well as by the growing number of available choices for buyers, and by suppliers with larger clientele and differentiated products and services. The forces that influence profitability in this industry is an essential part of strategic planning for any boiler and heat exchanger manufacturer that aims to control competition risk and optimize profitability. This research aims to break down and analyze the influences that industry manufacturers, market entrants, purchasers, component and raw material suppliers, foreign imports, technological advances, government policies, industry organizations, and future trends have on the profitability of industry players. While it was found that the level of competition in the industry is moderate, rapid advances in technology, increasingly stringent government policies on emission standards and boiler and heat exchanger efficiencies, as well as growing import competition may catalyze industry competition in the near future. The use of Porter's Five Forces in this analysis suggests the need to consider the significance of technology and the challenges posed by imports through increasing globalization, as these factors could substantially change and disrupt the industry by reducing barriers to entry and by raising the threat of substitutes. As a result, the boiler and heat exchanger manufacturing landscape in the US could become much more competitive, which in turn, could diminish returns for industry operators. This could also change the structure of the industry with the inception of industry players that offer differentiated products and services. The question for industry groups and policy-makers is to what extent should these five forces be influenced, since the degree of support for or of counteraction to these forces will guide the future competitiveness and marketization of the boiler and heat exchanger manufacturing industry in the US.

\section{Key words:}

boiler, heat exchanger, Porter's Five Forces, US manufacturing industry, industry competition 


\section{Introduction}

With the expansion of global trade and the technological progress made in countries with lower labor costs, manufacturers of boilers and heat exchangers in the US are facing ever growing import competition while simultaneously facing competition from industry rivals and market entrants. Profitability in the industry has also been eroded by the ever greater number of choices that buyers can seek from foreign imports as well as by suppliers with larger clientele and differentiated products and services. Understanding the forces that influence profitability in this industry is an essential part of strategic planning for any boiler and heat exchanger manufacturer that principally aims to mitigate competition risk and optimize profitability. Hitherto none of the previous scholarly research has examined the various forces that influence the industry from the perspective of Porter's (2011) five forces framework. While previous scholarly research has proffered comprehensive overviews of the industry, none of the research has, thus far, been dedicated to the various forces that influence the industry from the perspective of Porter's (2011) five forces framework. The framework deployed in this research provides a specialized analysis of the industry from the perspective of strategic management. The framework used in this analysis allows for top decision makers in the industry to competitively position their businesses by focusing on the forces and factors that wield the greatest influences on the industry. This research aims to break down and analyze in further detail the influences that industry manufacturers, market entrants, purchasers, component and raw material suppliers, foreign imports, technological advances, government policies, industry organizations, and future trends have on the profitability of industry players. Through analyzing and understanding each of these factors that shape the competition landscape in the boiler and manufacturing industry, current industry participants can strategically position themselves to be more competitive both at present and in the future.

This research aims to examine the boiler and heat exchanger manufacturing industry in the US through the theoretical application of
Porter's Five Forces framework. The goal is to develop a basic understanding on the competitive landscape for the boiler and heat exchanger manufacturing industry in the US. By determining the industry's 'structure' and its attractiveness, the five forces can help set an agenda for action on various critical issues such as the specific strategy to deploy in order to mitigate excessive rivalry in the industry (Whittington et al. 2020). This understanding allows for further analysis of individual manufacturers in terms of their particular valuechain advantage and strategically attractive competitive position.

This research commences with a preamble on why Porter's Five Forces framework was chosen as the method of conducting this research. This is followed by an outline of Porter's Five Forces and a further analysis of each one applied in the context of the boiler and heat exchanger manufacturing industry in the US. It will then proceed with the impact of technology, government policies, and current economic trends on the industry.

\section{Methodology}

\subsection{Analytical Framework}

Various analytical frameworks, tools, and marketing reports have been deployed in previous studies to assess the American boiler and heat exchanger industry. The author contends that the use of Porter's work (2011) in the five forces framework is particularly apt and insightful in analyzing the competitive landscape of the boiler and heat exchanger manufacturing industry through a focus on the industry's threat of new market entrants and substitutes, buyer and supplier power, competitive rivalry as well as other factors that significantly influence the industry such as technological and government policy impacts, and the current economic situation. An understanding of how these forces and factors influence the industry will help competitors strengthen its strategic management and competitive position in the industry.

While market reports have reported on the general competitive landscape of the boiler and heat exchanger manufacturing industry, the 
author's research focuses on the discussion of Porter's Five Forces and will analyze in further detail the technological trends that will shape the industry in the years to come. Current government policies that are shaping the industry, and the economic situation that is affecting the industry current as of the year 2020 will also be mentioned.

The author will examine the impact of technology, government policies and the current economic trends on the competitive field of the industry. The research will refer to a large extent on existing analyses of the boiler and heat exchanger industry in the US (Moses, 2019; Anesi, 2017; Rohr, 2020; Ohta, 1975; Albrecht et. al. 1992; Lynch, 2019; Lynch, 2020; McMenamin, 2019). In cases where those analyses are not available, the authors' insights will be relied upon. The research ends with a number of observations, insights, and recommendations for the industry to consider.

\subsection{Porter's Five Forces Analysis}

Porter's Five Forces framework is based on the notion that a firm's profitability is determined by industry attractiveness (Porter, 1985). Porter views the firm's profitability as being dependent upon competitive strategy to advance the interests of the firm. These rules of competitive strategy are rooted in the five competitive forces. Furthermore, he contends that:

"the strength of the five forces varies from industry to industry, and can change as an industry evolves" (Porter, 1985, p. 4)

so that all industries are mutually different from the perspective of "inherent profitability" (Porter, 1985 , p. 4). Critics of this framework such as Mintzberg (1994) have argued that the framework merely takes into account the view that strategy is only position rather than the view that strategy should be a matter of both position and perspective, since changing perspective while maintaining position in strategy may be difficult.

Porter's Five Forces consists of the following:

- Threat of New Entrants: The ease with which to enter the industry influences degree of competition. The greater the threat of entry, the worse it is for incumbents in an industry. An attractive industry has high barriers to entry that lower the threat of new competitors. Barriers to entry need to be overcome by new entrants if they are to compete in an industry (Whittington et al., 2020).

- Threat of Substitutes: A substitute offering differs from goods and services provided by industry competitors but that fill similar needs to what the industry offers. The threat of the substitute depends on the effective of substitutes in serving an industry's customers (Mastering Strategic Management, 2015).

- Supplier Power: Suppliers provide inputs that industry firms need to produce the goods and services that they in turn sell to their buyers. The relative bargaining power between an industry's competitors and its suppliers helps shape the profit potential of the industry (Mastering Strategic Management, 2015).

- Buyer Power: Buyers are the organization's immediate customers, not necessarily the ultimate consumers. Powerful buyers can demand low prices or costly product or service improvements. Buyer power tends to be high with concentrated buyers, low switching costs, buyer competition threat, and low buyer profits (Whittington et al., 2020).

- Competitive Rivalry: Competitive rivals are organizations that target identical customer groups and with similar products and services. These rivals, or 'incumbents' in an industry, are central to the five forces framework. The greater the competitive rivalry, the worse it is for these existing players (Whittington et al., 2020).

Porter (1985) is of the view that an organization's profitability gradually diminishes with a greater threat of entry, a greater threat of substitutes, stronger supplier and buyer power, and intensified competition amongst industry rivals. The effects of these five forces help answer Porter's two central questions in competitive strategy: the attractiveness of industries for long-term profitability and the factors that determine it; and the determinants of relative competitive position within an industry. 


\section{Analysis}

The competitiveness of a boiler and heat exchanger manufacturer can be attributed to several factors. As Moses (2019) has reported, these factors include the access to the latest available and most efficient technology and techniques, reliability of supply, a highly trained workforce, development of new products, and a reputation for quality and branding. He warns that the competition and the barriers to entry in this industry are both medium and increasing.

Porter (2011) mentions other factors such as the economic situation and the advent of technological advances and innovation as having significant influences on the five forces. These factors in addition to the five forces will have a major impact with respect to the boiler and heat exchanger manufacturing industry. These factors will be discussed in this study in relation to the five forces. Figure 1 outlines the forces from the perspective of the boiler and heat exchanger manufacturing industry in the US, and provides the framework for the discussion below.

\subsection{Threat of Entry}

Porter (2011) argues that the degree of the entry's threat to an industry is dependent on the "height of entry barriers" and on "the reaction entrants can expect from incumbents" (Porter, 2011 , p. 34). These barriers include supply-side economies of scale; demand-side benefits of scale; customer switching cost; capital requirements; incumbency advantages; unequal access to distribution channels; and restrictive government policy. According to Moses (2019), the growth of entrants in the industry has decreased as:

"the industry is in the mature stage of its industry life cycle" (Moses, 2019, p. 15).

\subsubsection{Supply-side economies of scale}

Supply-side economies develop from the production of larger volumes, thereby lowering unit costs, utilizing more efficient technology, or command better terms from suppliers (Porter, 2011). In the context of the boiler and heat exchanger manufacturing industry, this theory would mean mass production of packaged boilers or heat exchangers, an improvement in the boiler and/or combustion efficiency or technology, or negotiating for better terms with boiler component manufacturers. When packaged boilers or heat exchangers are built in larger volumes than custom-built units, the average cost per unit would be reduced. Albrecht et al. (1992) asserts that this production method together with the value analysis approach has resulted in value increases,

"achieving essential functionality at low cost in the power equipment industry" ( $p$. 37-1)

Furthermore, he states that:

In power station practice... depending on the load requirements, one or more units are purchased. In general, economics of scale dictate the purchase of the fewest number of units possible to meet overall load and system requirements. (p. 37-1)

Better terms from suppliers can be commanded in terms of the criteria required for new or replacement boilers such as boiler efficiency requirements, performance guarantees, environmental compliance, scope of supply including auxiliary equipment, commercial terms and conditions, project schedule, site access restrictions and evaluation criteria used in assessing design and operating tradeoffs (Albrecht et al., 1992). When the negotiation of terms from suppliers involves a bidding phase, the bid with the lowest cost usually wins (Power Engineering Second Class, 2015).

Another salient trait of supply-side economies is its deterrence of new entrants by forcing the entrant into the industry on a large scale, requiring they dislodge established boiler and heat exchanger makers. Alternatively, the new entrant will accept a cost disadvantage due to its initial relative deficiency in production scale and capacity, leading to a higher average cost per boiler/heat exchanger unit.

According to Moses (2019), boiler and heat exchanger manufacturers rely on input components from first tier suppliers include the paint manufacturers, the copper rolling, drawing and extruding industry, ferrous metal foundry producers, iron and steel manufacturers, and nonferrous metal foundry product manufacturers. $\mathrm{He}$ also mentions the industry's reliance on second tier suppliers would include valve manufacturers, metalworking machinery 


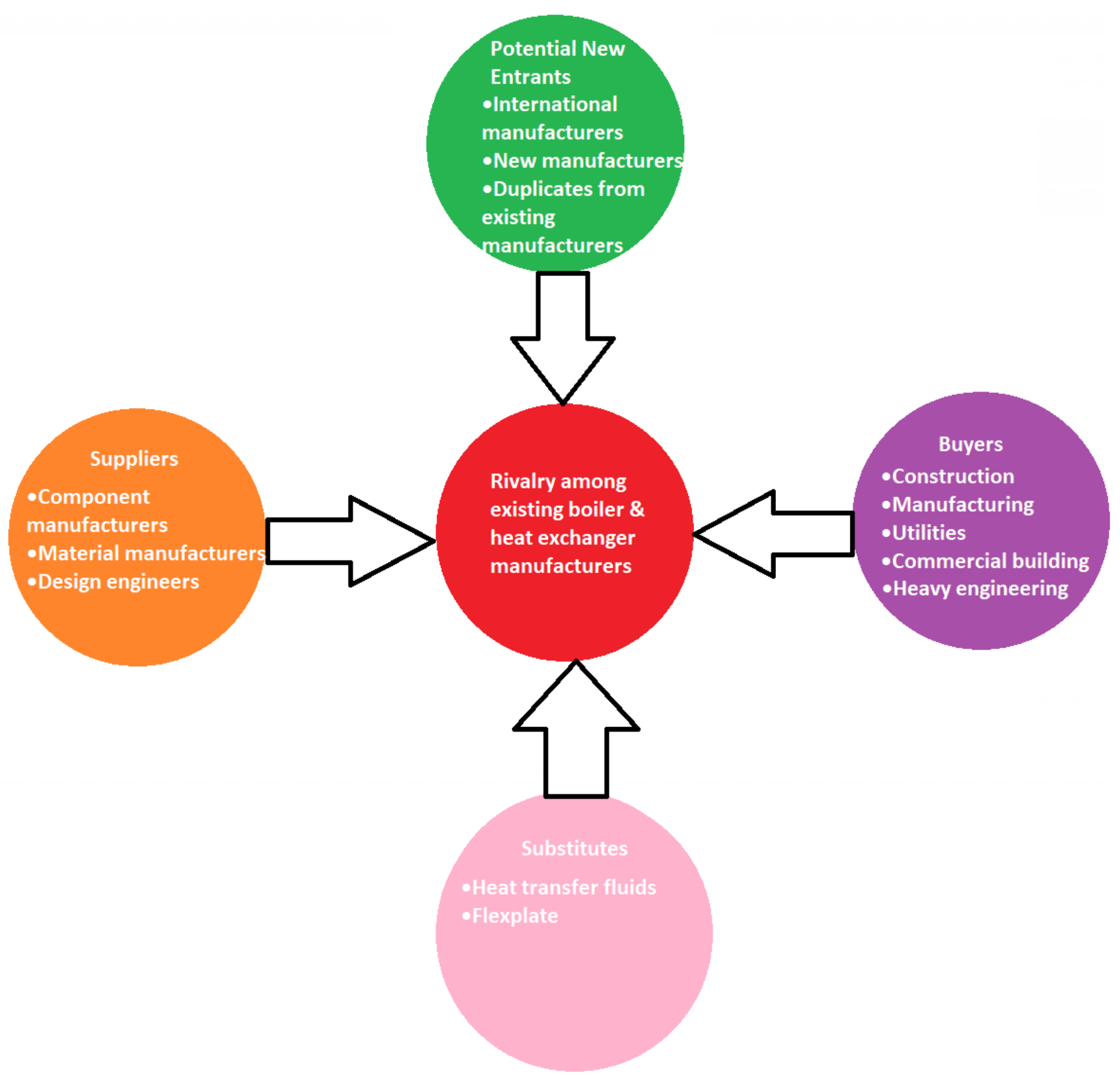

Figure 1. Boiler and Heat Exchanger Manufacturing Industry in the US viewed through Porter's Five Forces Framework.

manufacters and the industrial machinery and equipment wholesalers. Other industries that complement the boiler and heat exchanger manufacturing industry include the metal tank manufacturers, metal can and container manufacturers, and the heating and airconditioning contractors (Moses, 2019). While some industries such as the metal tank manufacturers, metal can and container manufacturers usually produce on demand. Other industries such as valve manufacturers, paint manufacturers, and metal producers tend to produce in bulk quantities. The large number of component manufacturers would mean that heat exchanger manufacturers may be able to negotiate better terms. In terms of supply-side economics, these industry incumbents would command greater power over its component suppliers.

\subsubsection{Demand-side benefits of scale}

According to Porter (2011), demand-side benefits of scale is also called network effects, These benefits arise in an industry where the rise in a buyer's willingness to pay for a company's product increases with the number of other buyers who also purchase from the company. Such benefits from charging price 
premiums may remain for the company so long as it does not oversupply the product, which would lead to customers demanding less of it (Thaler, 2009). Demand-side benefits of scale discourage entry by limiting the willingness of customers to purchase from a new entrant and by lowering the price the newcomer can command until it establishes a larger clientele (Porter, 2011).

In the context of the boiler \& heat exchanger manufacturing industry, as downstream buyers (for example, power plants, oil \& gas plants, hospitals, and commercial buildings) prefer to purchase new or replacement products that are more efficient, have higher performance, and/or are technologically more advanced, there is a higher demand for the same product, as this level of efficiency, performance, and/or technology becomes the new baseline in the industry. This new baseline results in other industrial competitors demanding the same boiler or heat exchanger units. Consequently, buyers may be willing to pay just as much if not more for these boiler and heat exchanger models to compete with their industry competitors in improving their production rates and efficiency. In this regard, the boiler or heat exchanger manufacturers with strong reputations for producing boilers or heat exchangers that are patented, reliable, highly efficient, technologically advanced, and safe are likelier to hold the greatest advantage when it comes to commanding price premiums in its products and services.

Another deterrent for new entrants in this industry are long-term contracts in place for existing businesses to supply industry products to various downstream industries, making it more difficult for new entrants to break into the boiler and heat exchanger market in the US.

The reputable and quality boilers and heat exchangers produced by manufacturers in the US are highly sought after within and outside the country. As Moses (2019) puts it,

"exports are substantial, and have risen as

a portion of industry revenue in

2019" (Moses, 2019, p. 33)

Growing demand from external markets for American boilers and heat exchangers have led to large manufacturers such as SPX to diversify into international markets.

For smaller and less known manufacturers, they are less likely to have earned a sufficient reputation and respect from buyers to command premium prices. In this regard, they may expand into foreign markets. For instance, Charter Industries, a smaller yet growing manufacturer, has set up manufacturing facilities in China, Germany and Easter Europe to cater to local demands (Moses, 2019). With respect to the US market however, the demandside benefit for these smaller manufacturers is realized to a lesser extent.

\subsubsection{Customer switching cost}

Porter (2011) defines customer switching costs as fixed costs that buyers face when they change suppliers. These costs arise when a buyer that switches vendors must alter product specifications, re-train employees to use a new product, or modify processes or information systems. Therefore, it becomes more difficult for an entrant to gain customers with higher switching costs (Porter, 2011). In this context, the supplier would be the boiler and/or heat exchanger manufacturer, and costs would incorporate all products and services that buyers would consider, including boilers, heat exchangers, and installation and technical support services. Switching costs for downstream buyers increases with distance from the manufacturer. One of the important considerations for downstream buyers is distance and by extension, delivery times and its reliability (Moses, 2019). The switching costs in the boiler and manufacturing industry in the US are considered low due to the presence of numerous manufacturers in the country with little dominance of the market for steam generating equipment. The lack of market supremacy even amongst the largest manufacturers in the US prevents any manufacturer from raising its prices significantly, since

"downstream companies can easily switch to a different industry operator for their purchases" (Moses, 2019, p. 32).

With switching costs being relatively low, downstream buyers of boilers and heat exchangers would be in a more affordable position to switch their purchases and services to other manufacturers based on product performance attributes:

"including strength to weight ratios, waterproof ability, malleability, corrosive performance, safety, installations costs and recyclability" (Moses, 2019, p. 32). 
An example of very high customer switching costs raised by Porter (2011) is the Enterprise Resource Planning (ERP). He states that once an ERP system is installed, the costs of moving to a new vendor are "astronomical". In the context of smaller boiler and heat exchanger manufacturers, ERP implementation comes with an exorbitant cost. As Peng (2017) explains, boiler supporting enterprises as well as other small and medium-sized manufacturing enterprises that require the implementation of ERP in order to use its cloud manufacturing platform services and applications may not have the financial capacity to do so due to the system's high costs of implementation. Even after a costly implementation of the ERP system, the costs of switching over to another ERP cloud manufacturing platform would be very high due to the factors that Porter (2011) has mentioned in regards to ERP switching costs.

\subsubsection{Capital requirements}

Ohta (1975) classifies various inputs of the boiler production industries into three groups: labor, materials, and capital goods. The intensive capital investment required for these inputs including infrastructure, machinery, materials, human resources, research and development, marketing and other overhead costs will reduce the threat of new entrants in the industry. The cost of materials may vary depending on whether the material of construction is based on carbon steel, stainless steel, nickel, and other metals such as alloys. Moses (2019) reports the significant costs for a new entrant when obtaining a workable manufacturing facility, combined with necessary plant and equipment maintenance and upgrades. This is a deterrent for some operators from entering the industry. Nonetheless, start-up costs may vary depending on operational scale and manufacturing location (Moses, 2019).

An investment of time and capital into human resources is also substantial since industry skills require on-the-job training, retraining and updating with the latest techniques and technology often at the manufacturer's expense. Moses (2019) explains that the large costs incurred for research and development is necessary for product innovation, which allows for the entrant to effectively compete through differentiating themselves from their competitors. High capital requirements for new entrants are exacerbated by the losses startups typically experience in the first three to five years of operation, as locations are being built and clientele is being developed (Moses, 2019).

\subsubsection{Incumbency advantages independent of size}

Established manufacturers of boiler and heat exchanger products have a strong incumbency advantage that are not available to potential entrants to the industry. Besides their established reputation in the industry, existing businesses may have long-term agreements in place to supply boiler or heat exchanger products to downstream industries. Further, they have patented production techniques and technologies which gives them an advantage over new entrants. For new entrants to build a portfolio of proprietary technologies, they would need to incur large costs on research and development in their initial years of company building. Moses (2019) reports that over the past ten years, advancements in the area of product development have focused on innovating more efficient models of products, along with maintaining a competitive cost structure by reigning in manufacturing and operating expenses. Such developments are made irregardless of company size. Incumbents with established networks are also at an advantage when it comes to sourcing less expensive components. Moses (2019) reports that some operators have begun to source castings, valves and machined parts from Asia to reduce purchase costs.

\subsubsection{Unequal access to distribution channels}

Porter (2011) explains the new entrant must secure distribution of its product or service. The more limited the wholesale or retail channels are and the more that existing competitors have tied them up, the more difficult entry into an industry will be. Larger boiler and heat exchanger manufacturers in the US tend to have their own sale distribution capabilities vertically integrated with their manufacturing capabilities. An example of such a company is Charter Industries, which has a market share of 
$2.0 \%$ (Moses, 2019). This firm is a manufacturer of power boilers and heat exchangers. The manufacturer also supplies, engineers, and develops its products to downstream users of the equipment (Boilers and Condensers , 2019). Another manufacturer, SPX Corporation, builds heat exchangers and cooling systems, supplies industrial buyers with its products in addition to providing engineering solutions, maintenance, and technical services. Modine Manufacturing Company is also an example of a verticallyintegrated manufacturer that not only builds heating and cooling products but also supplies them directly to downstream purchasers (Moses, 2019).

The large manufacturers mentioned above are examples of disproportionately greater access to markets due to their relatively vast financial wherewithal that allows these firms to achieve vertical integration. Likewise, this integration may be justified by the firms' greater economies of scale. A manufacturer that is capable of producing boilers and/or heat exchangers at a lower unit cost may also find it feasible to distribute their products at a lower unit cost. This may justify the presence of a company department dedicated to developing the market and selling directly to customers at a lower unit cost, thereby circumventing the intermediary distributor.

Some manufacturers may rely on boiler and heat exchanger suppliers to distribute their products. The difficulty new entrants may face in this situation is the tendency for buyers to seek out suppliers that have purchased units with a track record of being successful in boiler projects (Albrecht et al., 1992). Suppliers can troubleshoot problems quickly and minimize costly downtime when they provide valueadded services such as project management, maintenance support services when they have working knowledge of or are at least aware of the reputation and reliability of established boiler and heat exchanger products. For new entrants, it would likely take years to build a reputational foothold with product suppliers.

Whether or not unequal access to distribution channels may present a threat to the new entrant, another potential barrier that it faces may be the well-entrenched agreements that have been inaugurated with existing manufacturers to supply industry products to downstream industries (Moses, 2019).

\subsubsection{Restrictive government policy}

According to Porter (2011), government policy can hinder or aid new entry directly, as well as amplify (or nullify) the other entry barriers. In the context of the boiler and heat exchanger manufacturing industry in the US, the barriers to entry due to government regulations and policy are considered medium. Moses (2019) reports that the industry receives a "medium level of assistance" (Moses, 2019, p. 32), given several different tariffs on industry products. These tariffs are aimed at shielding American producers from competing imports. Additionally, legislative stipulations on the design, construction, and installation of boiler systems and and heat exchangers are requirements that current industry manufacturers are in a more favorable position to meet. These legislative specifications, in conjunction with stringent safety and product regulations, convey the synergistic effect of limiting competition for both new entrants and imports (Moses, 2019). Therefore, government policies appear to have a greater effect of empowering industry incumbents, which also have the financial disposal to form lobbying groups to influence and/or shape these policies.In summary, the potential barriers to entry are:

- The use of supply-side economies to deter new entrants by forcing the entrant into the industry on a large scale and limiting the willingness of customers to purchase from a new entrant and by lowering the price the newcomer can command until it establishes a larger clientele. For manufacturers who are entering the boilers and heat exchangers market, they would need to differentiate their products from industry competitors. By doing so, it may mitigate the effects that lowering prices would have on the market entrant.

- High capital requirements for new entrants are worsened by the losses start-ups typically experience in the first three to five years of operation. Therefore, a sufficient capital outlay or revenue generation is vital in order to keep the new entrant afloat in the early years of its establishment.

- Established reputations of industry incumbents and long-term agreements in place to supply boiler or heat exchanger products to downstream industries. The reputation of a market entrant takes time to build. As such, the market entrant's ability to 
differentiate from industry competitors will be a major determining factor in developing clientele in a niche market within the boiler and heat exchanger manufacturing industry.

- Tendency for buyers to seek out suppliers with a track record of being successful in boiler projects. A new entrant has not had enough time to prove itself in the boiler and heat exchanger market. As such, it would have to build trust and reputation with its clientele in its early phases in order to secure more contracts and orders in he future.

- Government policies tend to empower industry incumbents, which also have the financial disposal to form lobbying groups to influence and/or shape these policies. A market entrant would need to join these groups in order to exert its own influence. These groups would also allow the new boiler or heat exchanger manufacturer to network and to find common ground with other businesses within the industry association.

- Switching costs in the industry is considered low due to the numerous manufacturers in the country with little dominance of the market for steam generating equipment. This would present the market entrant with the opportunity to entice former clients of other industry competitors to try out the products of the market entrant. This can include adding value such as incentives, price reductions, and additional services.

After closer examination of the potential threats to entry as defined by Porter (2011), one can viably suggest that the barriers to entry in the boiler and manufacturing industry in the US would be medium and increasing (Moses, 2019). Accordingly, the declining threat of new entrants as one of the five forces pales in comparison to industry competitors.

\subsection{The power or suppliers}

In Porter's (2011) view, powerful suppliers capture more of the value for themselves by charging higher prices, limiting quality or services, or shifting costs to industry participants. Suppliers provide inputs that the firms in an industry need to create the goods and services that they in turn sell to their buyers (Mastering Strategic Management, 2015). While a portion of supplier power is comprised of valve manufacturers, metalworking machinery manufacturers, and industrial machinery and equipment wholesalers, the bigger contributors are the copper rolling, drawing and extruding businesses, ferrous metal foundry producers, iron and steel manufacturers, nonferrous metal foundry producers, and paint manufacturers (Moses, 2019). Suppliers in this industry are made up of firms that make parts and accessories such as valves, control instrumentation, steam traps, pipes and tubes, fans, actuators, and pressure relief valves for boiler and heat exchanger equipment. Other suppliers include those that provide goods and services manufactured for boiler and heat exchanger makers such as aftercoolers, barometric condensers, boiler casings, economizers, water storage tanks, and intercooler shells (Moses, 2019). Boiler manufacturers in particular, rely on input components based primarily on steel and aluminum including safety valves, water level indicators, pressure gauges, steam traps, boiler tubes, casing, insulation, fuel equipment, and circulating pumps from upstream suppliers.

While parts and material suppliers wield a medium level of power due to moderate levels of competition amongst suppliers, it may also vary from one supplier to another, depending on factors such as service and product reputation, quality, attributes, reliability, as well as agreements in place to supply the boiler and heat exchanger manufacturers. Switching costs tend to be very high for industry manufacturers with long-term contracts drawn up with upstream suppliers, which tend to command greater supplier power.

Suppliers of raw materials for the industry accounted for an estimated $44.7 \%$ of revenue as of 2019, according to Moses (2019). Depending on demand and the available supply of raw materials including steel, aluminum, alloys, corrugate, rubber, and paint, these suppliers may wield greater power when these materials are in shorter supply and/or in greater demand, and vice versa. However, as Albrecht et al. (1992) states, when commercially available materials such as alloys are found to be lacking in a given operation, new materials, which can provide the required mechanical and corrosion properties are developed to supplant these alloys. This would mean that supplier power would gravitate more towards those material suppliers with the technological 
expertise, labor and capital to be able to provide these more advanced materials. Raw material demand and thereby costs tend to be higher for boiler and heat exchanger manufacturers producing greater volumes of simpler products. However, as the level of complexity for the products increases, the costs of labor, capital, and technological expertise would in turn increase to represent a greater and greater percentage of overall costs. Therefore, the suppliers of these inputs can command greater supplier power with increased product sophistication. This power is further boosted by the fact that the boiler and heat exchanger manufacturing industry is not the sole market for these raw material suppliers, who can also supply their products to industries like the automotive, construction, machinery, and aerospace industries.

Upstream suppliers that offer parts and components are offering products that are differentiated and therefore, convey stronger supplier power. Suppliers that hold patented products, such as better insulation with more advanced materials or next generation combustion efficiency, may have no substitutes for what other suppliers are able to provide, and can therefore command more power vis-àvis makers of boilers and heat exchangers. These upstream suppliers of parts and components can also supply their products to industrial plants, power plants, commercial and residential buildings, as well as utilities and other facilities. Such diverse markets are also a source of power for upstream parts and component suppliers.

While makers of castings, valves, and machined parts and components hold a moderate level of power, industry operators have increasingly sourced these parts and components from regions such as Asia as part of reducing input costs. This trend towards greater import competition has inevitably resulted in lower switching costs and the erosion of power of upstream suppliers.

Due to the great number of upstream companies that supply to the boiler and heat exchanger manufacturers, the power held by suppliers may at best be considered as moderate.

Porter (2011) contends that a supplier group is powerful if:
- It is more concentrated than the industry it sells to (boiler and heat exchanger manufacturers),

- The supplier group does not depend heavily on the industry for its revenues,

Industry participants (boiler and heat exchanger manufacturers) face switching costs in changing suppliers,

- Suppliers offer products that are differentiated,

- There is no substitute for what the supplier provides.

The supplier group holds a favorable negotiating position and a strong degree of power for the raw materials, parts, and components suppliers to the industry, in spite of low supplier concentration that may not be dissimilar to the low concentration of the boiler and heat exchanger manufacturing industry. However, as Moses (2019) notes, the increasing presence of foreign competition and imports that offer more economical if not also better quality alternatives may weaken USbased supplier power and minimize the effects of switching costs.

\subsection{The Power of Buyers}

Porter (2011) describes powerful customers as the flip side of powerful suppliers, who can capture more value by forcing down prices, demanding better quality or more service, and generally playing industry participants off against one another, at the expense of industry profitability. Buyers are the organization's immediate customers, though not necessarily the ultimate consumers (Whittington et al., 2020). In the boiler and heat exchanger manufacturing industry, the key buying industries are the construction industry, manufacturers such as automotive manufacturers, commercial sector such as healthcare facilities, office buildings, and education facilities, heating and refrigeration, and TV \& appliance wholesalers. Other downstream buyers include breweries, home builders, and retail trade. Buyers have not been known to manufacture boiler and heat exchanger products on their own due to the hefty investment costs associated with infrastructure, research and development, human resources, machinery and equipment, marketing, and overhead.

There are relatively few market sectors that 
purchase products from the industry. According to Moses (2019), the automotive sector, commercial sector, exports, and heating and refrigeration sectors account for $46.1 \%, 24.3 \%$, $19.1 \%$, and $8.1 \%$ of total industry revenue, respectively. However, within each market sector, there are numerous downstream buyers, albeit that buy in small volumes relative to the size of a single manufacturer. Larger manufacturers tend to have buyers in multiple markets with which to provide industry products. Firms such as Graham Corporation makes products including steam jet ejector vacuum systems, surface condensers, vacuum pumps, and various types of heat exchangers for a wide range of industrial process applications that range from petroleum refineries, chemical and petrochemical plants to geothermal power plants, pharmaceutical plants, food processing plants and propulsion systems for nuclear aircraft carriers (Boiler and Condensers, 2019). Downstream buyers that deal with manufacturers of this scale may just be a small proportion of all the manufacturer's clients, and therefore may not command as much buyer power.

In the commercial sector, the value of utilities construction which reflects the downstream industries such as warehouses and retail in the commercial sector, has grown over the five years prior to 2019. Competition from less expensive imports is especially high, since commercial buyers tend to choose the most affordable boilers, hence buyers in this segment hold greater buyer power especially against US manufacturers with products that are standardized or undifferentiated. This trend is expected to increase as well. In the industrial sector where boiler and heat exchanger performance tend to hold a higher priority, high-performance boilers and heat exchangers usually built in the US are preferred by buyers. Moses (2019) reports that manufacturers such as SPX Corporation focuses on supplying industrial buyers with highly specialized engineered solutions, such as heat exchange and cooling systems. Buyer power in this case may be low in comparison since these types of boiler and heat exchanger products and services tend to be more differentiated.

Over the past five years to 2019, buyer power has grown significantly versus American manufacturers of boilers and heat exchangers with imported industry products as the primary drivers of this growth. According to Moses (2019), the value of imports in 2019 has reached approximately $\$ 2.5$ billion, nearly $20 \%$ of domestic demand for boilers and heat exchangers. The major sources of imports are Mexico, China, France, and Germany. However, more expensive imports from France and Germany have increasingly lost ground to less expensive products from Mexico and China, notwithstanding imposed tariffs that have led to sharp declines in Chinese imports. Buyer's preference for more economical boilers and heat exchangers underlies the increasing buyer power that they hold. Except for contracts that have already been established between manufacturers and buyers, the costs of switching industry vendors is relatively low especially when taking into account the significantly lower costs of imported boiler and heat exchangers.

In the Southwest region of the US, the food production industry constitutes a large major market for this industry (Moses, 2019). The entire supply chain for the food production industry is located in that region so that they can operate in close proximity with one another. It also follows that the boiler and heat exchanger makers would locate its manufacturing operations in close proximity to a primary downstream buyer (Moses, 2019). This makes switching costs in changing vendors costlier for the downstream buyers if switching to a manufacturer/dealer located significantly farther away.

Porter (2011) argues that a customer group has negotiating leverage if:

- There are few buyers, or each one purchases in volumes that are large relative to the size of a single vendor,

- The industry's products are standardized or undifferentiated,

- Buyers face few switching costs in changing vendors, and

- Buyers can credibly threaten to integrate backward and produce the industry's product themselves if vendors are too profitable.

In summary, the trend towards the purchase of imported boilers and heat exchangers notwithstanding tariffs imposed on imports of Chinese and foreign origin since 2018, as well as the low costs with switching to imports 
suggests greater power for the downstream buyer. Contrastingly, established contracts, and larger manufacturers with diverse client bases as well as those that have specialized or differentiated industry products, the difficulty for buyers to develop the same industry products, and the higher switching costs due to lower proximity suggest that buyer power is reduced. Hence, buyer power, having grown in the several years prior to 2019 due to the wider availability of imports, should be considered low to moderate when taking into account of its relativerelative weaknesses in the other criteria proofread proffered by Porter (2011) in addition to its juxtaposition with supplier power.

\subsection{The Threat of Substitutes}

Porter (2011) explains that a substitute performs the same or a similar function as an industry's product by a different means. Substitute products or services limit an industry's profit potential by placing a ceiling on prices. New industrial systems as well as those that use steam generation as the major source of power generation are setting up or retrofitting their systems to use heat transfer fluid systems as a primary means of generating energy. In recent years, heat transfer fluid (HTF) systems have gradually replaced and disrupted boilers and heat exchanger equipment that have traditionally used steam as the primary medium of providing energy at higher temperatures. HTF systems are industrial systems where a special heat transfer liquid other than water is circulated by a pump through a fired heat exchanger. Heat transfer fluids operate in either the vapour or more commonly liquid phase (Typical Industrial, 2017). Notwithstanding the potential hazards of extremely hot exposed piping systems, the very high flashpoints of HTF, and ignition hazard, HTF systems proffer a number of advantages over steam generating boilers and heat exchangers for processes operating in the temperature range of $200-$ $300^{\circ} \mathrm{C}$ (Typical Industrial, 2017). These advantages include higher energy efficiency, thermal stability, toxicity-free, ability to sustain higher temperatures at atmospheric pressure, low system pressures, high operating temperatures, no corrosion or freezing concerns, and circuit simplicity. Other advantages include no requirements for blow downs, steam traps, or condensate return systems, retubing filtering, and water treatment.
Also, if a process requires heating and cooling, it may be done with a single fluid, which is generally less expensive and simpler than vapour systems (Typical Industrial, 2017). Retrofitting a pre-existing industrial system that uses steam to operate with HTF's requires an overhaul and/or complete makeover of the majority of the system, and may therefore incur prodigious amounts of capital investment. While costs are high, it may still offer an attractive price-performance trade-off due to the following:

- Long-term cost savings in higher energy efficiency.

- Thermal stability of the HTF

- Lower heath costs for plant personnel due to the HTF being non-toxic.

- Reduced piping costs associated with low system pressures.

- Lower maintenance costs when corrosion or freezing poses a much smaller risk of damage to piping, fittings, and equipment.

- Lower replacement costs for fittings.

- Lower filtering issues.

- No water treatment costs required since the HTF system is closed.

- No cross-contamination concerns since a single fluid is used.

In the case of a new industrial system, costs that range from engineering design and planning, to management, procurement, construction, and commissioning are included from the commencement of the project. Hence, the costs of switching to HTF systems is contrastingly much lower than the modernization of an existing plant. For a new industrial system, the price-performance ratio is even more favorable than that of plant retrofitting, which tends to bear the heftier costs of re-engineering, reconstruction, retraining, and higher costs associated with the more complex retrofitting process and hence the greater potential for errors during each phase of the retooling project. Another potential substitute for steam generating boilers and heat exchangers are pump-type hydronic systems which use condensing boilers. Water-based hydronic systems use a heat source, a distribution system, and a heat emitter to transport thermal energy in a system that resembles a drive belt (Siegenthaler, 2012) to achieve lower thermal losses, lower distribution energy requirements, and higher efficiency than 
typical forced air systems. Hydronic systems that use condensing boilers thrive at lower operating temperatures in the condensing mode. Rohr (2020) reports that this system also allows for better flexibility in transferring energy to the distribution system and can be designed using heat sources such as heat pumps, solar and reclaimed heat. This flexibility adds value for the client and enhances product differentiation, thereby giving hydronic systems a competitive edge over industry competitors. In general, the lower the operating temperature of a modern boiler, the higher the efficiency is due to a lower standby loss and less heat loss that leaves the flue stack (Rohr, 2020).

The hydronic system also offers an attractive price-performance ratio for commercial and residential buildings. The costs of switching to hydronic systems with condensing boilers from more traditional forms of heat distribution tend to be low, since hydronic systems tend to involve a much smaller retrofitting footprint. The majority of the technology used in hydronic systems are well-established and costs less in system design, construction, and project management. Moses (2019) reports that heat pumps that collect heat using air, water or geothermal energy may develop into a competitive substitute for industry products as the demand grows for energy-efficient and environmentally friendly sources of heating energy.

Porter (2011) argues that the threat of a substitute is high if:

- The substitute offers an attractive price and performance relative to the industry's product.

- The buyer's cost of switching to the substitute is low.

In summary, the threat of substitutes may be considered high as the trend of recent years is for new and existing plants to implement or retool systems to use either HTF or hydronics. When it comes to plant retrofitting, the costs of switching to HTF systems are high due to the vast scope of the project scale and costs. However, for new industrial systems, the lower price tag of the HTF project and the greater number of years that the plant system can operate, give HTF significant advantage. Hydronic systems are the more common threat in commercial and residential buildings. The cost of retrofitting a building is lower since hydronic systems require a lower level of system, equipment, and piping. Likewise, the price-performance ratio is high for these types of systems. Hence, the threat of substitute of hydronic systems is high.

\subsection{Rivalry Among Existing Competitors}

Porter (2011) argues that rivalry among existing competitors takes many familiar forms, such as price discounting, new product introductions, advertising campaigns, and service improvements. In the boiler and heat exchanger manufacturing industry, the intensity of rivalry hinges upon the competition's target: customers, engineers, patents, and government incentives. According to Moses (2019), this rivalry can be defined further by examining the dimensions of rivalry: price, and non-price dimensions.

\subsubsection{Price Dimensions}

Porter (2011) contends that rivalry is destructive to profitability if it gravitates solely to price because price competition transfers profits directly from an industry to its customers. If price competition is sustained, it also trains customers to pay less attention to product features and service. For this reason, manufacturers that have been able to differentiate their boilers or heat exchangers from competitors are still profitable even if they raise their prices. Moses (2019) reports that the majority of industry products are sold to food and beverage processors and industrial construction operators, which are constantly searching for cheaper alternatives. This may be due to the similar types of boilers and heat exchangers that are used in the food and beverage industries as well as industrial construction operators. Hence, the only way to differentiate from competitors is to reduce prices. Industry operators set prices to offset direct costs in addition to a percentage profit contribution. Many industry players also set different price structures depending on the market that they sell to (Moses, 2019).

\subsubsection{Non-Price Dimensions}

Porter (2011) argues that competition on dimensions such as product features, support services, delivery time, or brand image is less 
likely to erode profitability because it improves customer value and can support higher prices. According to Moses (2019), buyers of boiler and heat exchanger products seek quality to increase the value of their purchases. Manufacturers that are able to build quality into their boiler and heat exchanger products are usually better able to safeguard their reputation. Such businesses are better positioned to hold onto long-term clients and business relationships as a result of providing this value to downstream buyers. Among the product performance attributes that influence competition include strength to weight ratios, waterproof ability, malleability, corrosive performance, safety, installation costs and recyclability (Moses, 2019). He has also mentioned other possible attributes may include product lifespan and durability, combustion efficiency, fuel flexibility, serviceability, frequency of maintenance and cleaning, susceptibility to leakage, maximum allowable working pressure, and hydrostatic performance. Moses (2019) has reported that to gain business, manufacturers must build quality into their products, materials, specifications, safety features, parts, delivery and service. Furthermore, the aforementioned attributes can be enhanced and differentiated through technological innovation, that is, through internal research and development (Moses, 2019). For example, Modine, a global leader in heating and cooling technology, will remain competitive through the product quality that comes from its investments in technological advancements in spite of increased price pressures from imported products (Moses, 2019).

Besides product quality, the reliability of delivery times and other services such as design advice allow competitors to differentiate themselves from other competition. Contracts based on competitive bidding provide a platform for industry players to compete on design, construction and installation of boilers and heat exchangers, supporting the notion that the level of industry competition is medium, according to Moses (2019).

Porter (2011, p. 44) states that the rivalry amongst industry competitors is most intense if:

- Competitors are numerous or are roughly equal in size and power.
- Industry growth is slow.

- Exit barriers are high.

- Rivals are highly committee to the business and have aspirations for leadership, especially if they have goals that go beyond economic performance in the particular industry.

- Firms cannot read each other's signals well because of lack of familiarity with one another, diverse approaches to competing, or differing goals.

In summary, since prices may not be significantly raised by industry manufacturers due to considerations that downstream buyers may readily switch to a different industry operator for their purchases, the intensity of rivalry, from the perspective of price dimensions, may be low. However, non-price attributes such as product and service quality, as well as delivery times would become the determining factor in the competitive edge of each boiler and heat exchanger manufacturer and the intensity of rivalry amongst industry competitors.

\subsection{Government}

Porter (2011) argues that government is not best understood as a sixth force because government involvement is neither inherently good nor bad for industry profitability. Government operates at multiple levels and through different policies, will influence the five competitive forces. Environmental concerns have led to upward pressure on boiler and heat exchanger efficiency in recent years. Moses (2019) reports that from 2014 to 2019, the US Department of Energy issued requirements to raise efficiency standards for residential boilers and furnaces that will be implemented for the 2019 to 2024 time period. The effect of these new requirements on demand may neither be good nor bad for the industry. While it would be expected that the rise in efficiency standards would raise the demand for industry products with better performance rates in combustion efficiency, the additional costs of raising efficiencies incurred from research and development, retooling of manufacturing facilities, and marketing are expected to be passed on to the customers. Hence, these price increases in addition to replacement costs may to some extent dampen the demand for more efficient boilers and heat exchangers. 
Moses (2019) reports that the effect of government regulations and recommendations on demand in this industry is significant on household consumers since official sources of information on residential boilers, which is typically written in technical jargon, is commonly relied upon when making purchase decisions. The effect of these regulations and recommendations may become more attenuated for purchasers of industrial boilers. These purchasers are usually engineers or managers with a technical background, and tend to have a better understanding of the boilers and heat exchangers that they are looking to purchase.

Overall, the level of regulation is medium and is increasing as regulations gradually demand better efficiency and waste disposal in the manufacturing process (Moses, 2019). Such regulations are a positive development in that they can potentially enhance the product performance and production efficiency of the boiler and heat exchanger manufacturing industry. Environmental legislation such as the Clean Air Act [2019] establish allowances for sulfur and nitrogen oxides as well as ozone emissions and other toxic materials released by the metal fabrication industries (Moses, 2019). This would load upstream suppliers with more costs, unless they are able to pass on these costs on to industry participants. In order to successfully pass on these costs, these suppliers would need to command sufficient supplier power over their manufacturing clients.

\subsection{Current Economics}

An industry analysis also needs to consider the current economic circumstances and their impacts on the five forces as previously stated. In light of the recent coronavirus pandemic that has gripped the global economy since the first quarter of 2020, the boiler and heat exchanger industry has been severely affected by the contraction of the US economy despite the industry's planning and implementation of procedures and precautions to ensure the health and safety of their employees. When the Department of Homeland Security's Cybersecurity and Infrastructure Security Agency (CISA) outlined the businesses and infrastructure that were deemed essential in March 2020, amongst the sectors listed under essential infrastructure was the Critical
Manufacturing Sector (Identifying Critical, 2020). At the time of this research, the boiler and heat exchanger manufacturing industry has still not been included in this sector according to CISA's official website. When it was realized that the boiler and heat exchanger manufacturing industry was not included in the initial CISA list of essential businesses and infrastructure, Lynch (2020), the President and CEO of the American Boiler Manufacturers Association (ABMA), requested for support to designate, in their states and localities, the boiler industry and all manufacturing facilities, supply chains and their employees as "essential infrastructure" and "essential businesses". This request was made, in partnership with the National Association of Manufacturers, in an effort to mitigate the economic impact that the pandemic shutdown was having on the industry.

The ongoing coronavirus crisis has led to the emergence of the rental boilers industry as boilers have been at near capacity at many hospitals and food processing facilities across the US (Lynch, 2020). Whether this rise in demand for a temporary solution to the capacity issue may affect demand for the purchase of new boilers remains to be further observed.

In a time of economic crisis, the ABMA has also shifted its strategy from its emphasis on being an association of strictly manufacturers of boilers and boiler-related products to an association focused on the entire boiler supply chain. The industry association has also planned for the launch of the BOILER 2021 ABMA Boiler Technology Conference \& Expo in October 2021 to connect manufacturers with customers engaged in the purchasing, operation, and maintenance of boilers such as boiler operators, engineers, facility mangers, heads of procurement, contractors, technicians, consultants, and others (ABMA Announces, 2020). This allows for the boiler supply chain in the industry to network with each other. Furthermore, business relationships can be built from this event. According to Viskup (2020), the BOILER 2021 event is a:

"totally new and uniquely tailored show for boiler people, presented by boiler people" (Viskup, 2020, p. 26),

focused specifically: 
"at the end-user community, most notably, influencers having responsibility for boiler room operations" (Viskup, 2020, p. 27).

This event is also a response to customer concerns that there is:

"not enough boiler-related content at major trade shows" (Viskup, 2020, p. 27),

and to:

"align the organization around the real-time requirements of all industrial and utility sectors" (Viskup, 2020, p. 27).

The historic lack of conferences and exhibition events pertinent to the boiler and heat exchanger manufacturing industry has also made it more difficult for the industry at the dawn of the current economic recession.

\subsection{Technology}

Porter (2011) argues that advanced technology or innovations are not by themselves enough to make an industry structurally attractive or unattractive. He believes that mundane, lowtechnology industries with price-insensitive buyers, high switching costs, or high entry barriers arising from scale economies are often far more profitable than "sexy" industries, such as software and internet technologies, that attract competitors. While this may be true of some industries that are less technologicallydependent, the boiler and heat exchanger manufacturing industry is one that was born and developed out of scientific and technological advances. These advances, particularly if they are patented and offer improved value, make it arduous for competitors to enter the competition and allow the firm to raise prices for technologies that are difficult to replace and that are heavily demanded or needed. Technological differentiation also make it unfeasible and ultimately costlier for buyers to switch to another product with inferior technological features that offer lower value. In order to compete in the US boiler and heat exchanger market, Moses (2019) has recommended a commitment to spending a significant amount on developing new product lines to differentiate from industry competitors. Through product differentiation, clients would be offered greater value that can only be offered by the product's manufacturer.
Ohta (1975) has stated that the most emphasized parameters in the development of boiler and heat exchanger technology are capacity and efficiency. He has also asserted that boiler ratings and its megawatt rating have a tendency to increase over time. As mentioned earlier, the US Department of Energy's requirements for more efficient boilers and heat exchangers has already pushed industry players to invest more into developing the efficiency of their products. The extent of the price increases required to recuperate the costs of research and development will largely determine the value offered by new products. Nevertheless, there have been industry players that have stepped up to the challenge posed by the recent government requirements. McMenamin (2019) reports that companies such as Armstrong Fluid renewed its pledge to reduce greenhouse gas emissions among its installed customer base by 2 million tons by the year 2022.

Technological advancements made by manufacturers may provide value for the downstream buyer. These advancements include new electric water heaters and boilers designed for regions that generate electricity through renewable sources of energy for use in powering plumbing applications on the grid. Other products include the point-of-use electric water heater targeting the market for nursing homes and office spaces, and the Europeaninnovated micro CHP cogeneration product, the XRGI25, designed to be an efficient and easyto-install system used for light commercial applications (McMenamin, 2019). The technological development of boiler and heat exchanger products are trending towards customization and user-friendliness. This direction in technological progress may enhance value for the downstream buyer by tailoring the product's features to buyer needs. Computer-assisted design (CAD) and manufacturing (CAM) have already become a ubiquitous technology in this industry (Moses, 2019). As software used in the design and manufacturing process develops to integrate smart internet technology and big data as well, this will improve cost structure by reducing time from design to production, particularly for custom-built and designed boilers and heating installations. 
A potential cost that manufacturers may have to confront is the cost of retraining end-users of the new technology. As Lynch (2017) puts it, the companies that represent ABMA want to help end-users use their products more efficiently and make sure installers understand and are educated with the technology changes. Based on the above factors, competition in the industry is medium and will continue to grow as public concerns on climate change, as well as government requirements for more efficient boiler and heat exchangers with lower greenhouse emissions grow. These public and government demands will provide an impetus for the industry to innovate new products and services well into the future. Furthermore, Lynch (2017) has predicted that future trends in the boiler market will include increased modularization, minimizing site work; growth in connectivity demands; and comfort heating moving to hot water (Anesi, 2017).

\section{Conclusion}

Applying Porter's Five Forces to the boiler and heat exchanger manufacturing industry in the US has allow us to better understand the competitive landscape in which the industry is currently found. This awareness also helps the industry to better adapt to and cope with challenges posed by rivals, market entrants, as well as by regulatory and technological changes.

This research has set out to analyze the competitive situation of the boiler and heat exchanger manufacturing industry in the US through the application of Porter's Five Forces framework. This framework aims to outline the effects of supplier and buyer power, threat of entrants, and industry rivalry as moderately powerful forces in the industry that lead to the erosion of profitability. It is noteworthy to mention that with the technological advances in the industry and government policies strengthening requirements for boiler and heat exchanger products with enhanced efficiency and lower emissions, power may shift towards industry competitors that can prove that they can adopt or outperform this trend. Changing technology may further shift the power balance from the buyer and the supplier towards industry incumbents and market entrants that are more technologically competent.

Government policies may also influence the competitive landscape if they provide appealing incentives to buyers for purchasing boilers and heat exchangers with higher efficiencies and lower rates of emission. It would lead to greater financial power for buyers, but also to industry rivals and market entrants that are technologically positioned to benefit from these new policies. Government policies, however, have a greater effect of empowering industry incumbents, which collectively have the financial resources to form lobbying groups to influence and/or shape these policies. In this regard, the market entrant and imports are limited by such policies. According to Moses (2019), the boiler and heat exchanger manufacturing industry receives a moderate level of direct assistance in the form of tariffs on imports, which reduce import penetration in the domestic market. If the government imposes more tariffs on imports, more power may shift towards industry rivals and market entrants. Conversely, if new government policies decide to lower tariffs on imports, the buyer would gain power while the industry competitor, market entrant, and supplier would all stand to lose.

For industry groups and policy-makers, this analysis would suggest the need to consider the significance of technology and the challenges posed by imports through increasing globalization, as these factors could substantially change and disrupt the industry by reducing barriers to entry and by raising the threat of substitutes. As a result, the boiler and heat exchanger manufacturing landscape in the US could become much more competitive, which in turn, could diminish returns for industry operators. This could also change the structure of the industry with the inception of industry players that offer differentiated products and services. The question for industry groups and policy-makers is to what extent should these five forces be influenced, since the degree of support for or of counteraction to these forces will guide the future competitiveness and marketization of the boiler and heat exchanger manufacturing industry in the US. 


\section{Acknowledgment}

The author is grateful to the anonymous reviewer whose valuable comments helped in refining and improving this manuscript. The author declares no competing interests nor any external funding for this research.

\section{Cite as:}

Chik J. 2021. An Analysis of the Boiler and Heat Exchanger Manufacturing Industry in the US Using Porter's Five Forces Framework. Alberta Academic Review, Vol 4(2) p1-18, DOI: 10.29173/aar116

\section{References}

ABMA Announces BOILER 2021. Today's Boiler. 2020. ABMA. Spring 2020: 10. [accessed 2020 Aug 20]. https:// abma.caboodleai.net/en/article/68340/abmaannounces-boiler-2021-abma-boilertechnology.

Albrecht MJ, Alexander KC, Andrews JB, Blue JD, Branigan GH, Campobenedetto EJ, Carlton JD, Childress PC, Cioffi PL, Clark GA, et al. 1992. Steam/its generation and use. 40th ed. Barberton (OH): The Babcock \& Wilcox Company. p. 37.

Anesi J. 2017. Inside an industry institution. Plumbing \& Mechanical.; p. 66.

Boilers and Condensers (Including Nuclear Reactors) and Heat Exchangers Manufacturing Industry (U.S.). 2019. Analytics, Extensive Financial Benchmarks, Metrics and Revenue Forecasts to 2016, NAIC 332410. Houston (TX): Plunkett Research, Ltd.

Clean Air Act [Internet]. 2013. Washington (DC): United States Environmental Protection Agency. [accessed 2020 Sep 25] https:// www.govinfo.gov/content/pkg/USCODE-2013title42/html/USCODE-2013-title42-chap85subchapl-partA-sec7412.htm

Identifying critical. [Internet]. 2020. Critical Manufacturing Sector, Washington (DC): Department of Homeland Security. [accessed2020 Sep 16]. https://www.cisa.gov/ critical-manufacturing-sector

Lynch S. 2017. Moving the Needle - Promoting Our Industry. Today's Boiler.p. 3.

Mastering Strategic Management. 2015. Minneapolis (MN): University of Minnesota Libraries Publishing. p. 88-99.

McMenamin E. 2019. AHR Expo 2019: Trends and themes from the show floor. PM Engineer. 02.19: 25-26.

Mintzberg H. 1994. The fall and rise of strategic planning. New York (NY): The Free Press. p. 26-48.

Moses J. 2019. US Industry (NAICS) Report 33241, Boiler \& Heat Exchanger Manufacturing in the US. IBIS World Inc.

Ohta M. 1975. Production Technologies of the U.S. Boiler and Turbogenerator Industries and Hedonic Price Indexes for Their Products: A Cost-Function Approach. Journal of Political Economy. Chicago (IL): The University of Chicago. 83(1): p. 9, 11.

Peng Z. 2017. Analysis of the ERP Implementation Capability of Small and Medium Manufacturing Enterprise ERP before Implementation in Cloud Manufacturing Environment - A Case Study of Boiler Accessories Enterprise. [accessed 2020 Sep 2] p. 426-427. doi: https://doi.org/ 10.1145/3176653.3176687

Porter M. 1985. Competitive advantage: creating and sustaining superior performance: with a new introduction. New York (NY): The Free Press.

Porter M. 2011. The Five Competitive Forces That Shape Strategy. Boston (MA): Harvard Business Review Press. 79(3): p. 31-56.

Rohr B. 2020 Feb. Turning down the temperature. Mechanical Business. 02.20: $p$. $46,48$.

Siegenthaler J. 2012. Modern Hydronic Heating: For Residential and Light Commercial Buildings. Third Edition. Delmar Cengage Learning. Chapter 1, Fundamental Concepts; $p$. 3.

Thaler R, Sunstein C. 2009. Nudge. New York (NY): Penguin Book. p. 99.

Typical Industrial Plant Configurations. 3rd Ed. 2017. Calgary, Alberta, PanGlobal Training Systems. p. 1-13.

Viskup J. 2020. BOILER 2021: The Right Time, The Right Show. Tulsa (OK): HPAC Engineering. [accessed 2020 Aug 15]. https:// www.hpac.com/heating/article/21133100 boiler-2021-the-right-time-the-right-show.

Whittington R, Regner P, Angwin D, Johnson G, Scholes K. 2020. Exploring Strategy. 12th ed. Hawlow, UK: Pearson. Chapter 3, Industry and sector analysis; p. 62-90. 